\title{
Thermodynamic Analysis of Resources Used in Thermal Spray Processes: Energy and Exergy Methods
}

\author{
Kamran Taheri ${ }^{1, *}$, Mohamed Elhoriny ${ }^{1}$, Martin Plachetta ${ }^{1}$ and Rainer Gadow ${ }^{1,2}$ \\ 1 Graduate School of Excellence Advanced Manufacturing Engineering (GSaME), University of Stuttgart, \\ 70569 Stuttgart, Germany; Mohamed.Elhoriny@gsame.uni-stuttgart.de (M.E.); \\ Martin.Plachetta@gsame.uni-stuttgart.de (M.P.); Rainer.Gadow@ifkb.uni-stuttgart.de (R.G.) \\ 2 Institute for Manufacturing Technologies of Ceramic Components and Composites, University of Stuttgart, \\ 70569 Stuttgart, Germany \\ * Correspondence: kamran.taheri@gsame.uni-stuttgart.de; Tel.: +49-711-685-68221
}

Academic Editor: Kevin H. Knuth

Received: 31 March 2016; Accepted: 17 June 2016; Published: 24 June 2016

\begin{abstract}
In manufacturing, thermal spray technology encompasses a group of coating processes that provide functional surfaces to improve the performance of the components and protect them from corrosion, wear, heat and other failings. Many types and forms of feedstock can be thermal sprayed, and each requires different process conditions and life cycle preparations. The required thermal energy is generated by a chemical (combustion) or electrical (plasma/or arc) energy source. Due to high inefficiencies associated with energy and material consumption in this process, a comprehensive resources used analysis for a sustainable improvement has always been promising. This study aims to identify and compare the influence of using different forms of feedstock (powder, suspension) as well as energy sources (combustion, plasma) on efficiency and effectiveness of energy conversion and resources consumption for different thermal spray processes based on energy and exergy analysis. Exergy destruction ratio and effectiveness efficiency are used to evaluate the energy conversion efficiency. The degree of perfection and degree of energy ratio are applied to account for the intensity of resources consumption (energy or material) in thermal spray processes. It is indicated that high velocity suspension flame spray has the lowest effectiveness efficiency and the highest exergy destruction compared to other thermal spray processes. For resource accounting purposes, in general, suspension thermal spray showed the lower degree of perfection and accordingly the higher inefficiency of resources used compared to powder thermal spray.
\end{abstract}

Keywords: energy; exergy; effectiveness efficiency; thermal spray; resources

\section{Introduction}

The main purpose in manufacturing is to transform raw materials into useful products. The seemingly extravagant use of processing and auxiliary materials as well as energy by many newer manufacturing processes is alarming and needed to be addressed alongside claims of improving sustainability [1]. Thermal spray process is an energy and resource intensive manufacturing process in which thermal energy is generated from electrical plasma/arc or fuel combustion. These energy sources are used to heat the coating material (for example, powder and suspension) to a molten state. The resultant heated particles are accelerated and propelled toward the workpiece by either process gases or atomization jets. Inefficiency of the process in coating deposition as well as energy conversion can have significant effects on environment and sustainable use of resources [2]. Thermodynamics is introduced as a well-suited method to analyze the magnitude of these effects as well as the efficiency of the energy transformation $[3,4]$. 
To manufacture diverse coating quality, different types of feedstock (such as powder and suspension) can be applied in thermal spray [5-7]. However, the question has been raised regarding the impact of using different forms of feedstock on energy conversion efficiency and intensity of resource consumption in accordance with the type and characteristics of the applied thermal spray technique. In this work, atmospheric plasma spray (APS), suspension plasma spray (SPS), high velocity oxy-fuel spray (HVOF) and high velocity suspension flame spray (HVSFS) are investigated. Thermodynamic methods are applied for process evaluation and resource accounting. The analysis approach includes:

- process effectiveness efficiency and exergy destruction analysis to measure process performance in energy conversion and deviation from optimal condition;

- $\quad$ resources used analysis to identify and allocate the intensity consumption of resources (energy or material).

The general overview of the advantages of using exergy analysis in comparison with conventional energy analysis for evaluation of thermal spray process inefficiencies was discussed [8]. However, this study provides a detailed useful insight into various exergy-based methods to highlight the inefficient use of resources, with an emphasis on both process evaluation and resource accounting. It is underlined that integration of the results of energy conversion efficiency and resource accounting provides a framework for identifying, comparing and prevention of the inefficiencies associated with the resources used.

For exergy efficiency and exergy destruction analysis, the spray torch was considered as the analysis boundary where the input energy is converted to the heat for melting/vaporizing of the powder/suspension feedstock. For the effectiveness efficiency and resource accounting, the analysis boundary was extended to the coating as the useful product.

\section{Analysis Methodologies}

Exergy analysis of thermal system has been practiced by many authors [9-12]. Exergy methods provide complementary useful information to conventional energy assessments. In general, performance of the manufacturing systems can be described in thermodynamic terms by formulating energy, mass and exergy balance. For the thermal spray process, energy in the form of electrical plasma or fuel combustion is converted to heat, which is partly removed as the heat loss by the process cooling. Then, the useful heat is transferred to the gas mixture of the flame/plasma down the nozzle jet to melt and accelerate the feedstock on to the surface of the workpiece. The energy and exergy balance of the thermal spray torch are as follows.

\subsection{Energy Balance}

The general energy balance of the torch in thermal spray can be written as:

$$
\begin{aligned}
& \text { Energy input }- \text { Heat loss to the cooling water }=\text { Heat output } \\
& \qquad \dot{W}_{F}-\dot{Q}_{l}=\dot{Q}_{o u t}
\end{aligned}
$$

where $\dot{W}_{F}, \dot{Q}_{l}$ and $\dot{Q}_{\text {out }}$ are the input energy, heat loss and heat output rate, respectively. Cooling water is required to increase the lifetime of the torch [2]. It is assumed that the net conductive, radiative and electrode heat losses of the torch are removed by the cooling water and can be evaluated as below:

$$
\dot{Q}_{l}=\dot{m}_{w} c_{w} \Delta T
$$


where, $\dot{m}_{w}$ and $c_{w}$ are the mass flow rate and specific heat at constant pressure of the water, and $\Delta T$ is the temperature difference between inlet-outlet temperatures of the water circuit. Hence, the thermal (energy) efficiency of the torch becomes:

$$
\eta_{e n}=\frac{\dot{Q}_{o u t}}{\dot{W}_{F}}
$$

\subsection{Exergy Balance}

Considering the spray torch as an analysis boundary, Figure 1 shows schematically the input-output exergy flows of the torch.

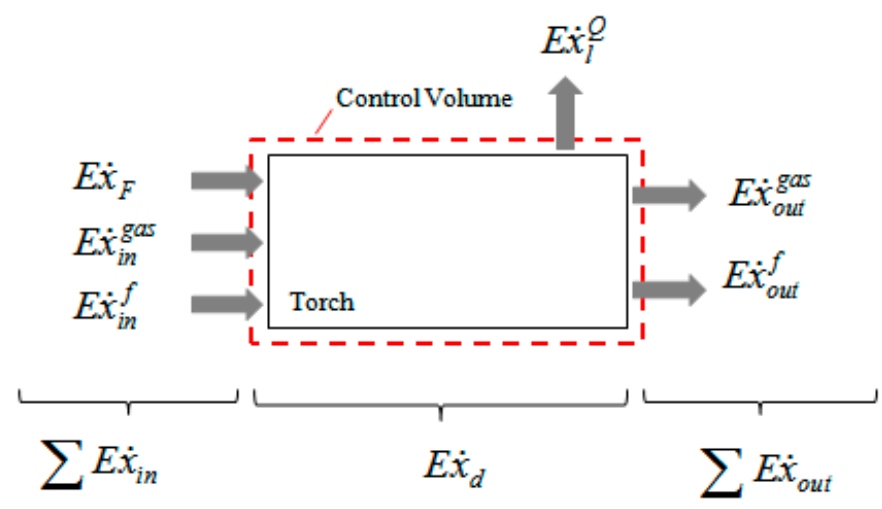

Figure 1. Exergy balance for thermal spray torch boundary.

From the exergy balance in Figure $1, \sum \dot{E} x_{i n}, \sum \dot{E} x_{\text {out }}, \dot{E x_{d}}$ are the total exergy input, output and destruction rate, respectively. Specifically, $\dot{E} x_{F}, \dot{E x_{i n}^{g a s}}$ and $\dot{E} x_{i n}^{f}$ are the input energy, gas mixture and feedstock exergy rates. $\dot{E x_{\text {out }}^{f}}$ and $\dot{E} \dot{x}_{\text {out }}^{g a s}$ are the feedstock and gas mixture exergy rates in the outlet jet. $\dot{E x_{l}^{Q}}$ is the exergy rate of the total heat loss. The general exergy balance for the thermal spray torch can be written as follows:

Exergy input - Exergy of heat loss to the cooling water - Exergy destruction $=$ Exergy output

For each single gas/feedstock stream of the jet, the steady-state exergy rate balance is as Equation (6). Depending on type of thermal spray process, the outlet jet may consist of process gases, combustion products and feedstock. Here, the total exergy associated with a specific state of a flow is the sum of thermomechanical/physical and chemical exergy. By definition, physical exergy is the work obtainable by taking the substance through reversible physical processes from its specific state $(T, p)$ to the atmospheric state $\left(T_{0}, p_{0}\right)$. Chemical exergy is the work that can be obtained when the considered substance is brought into reaction with reference substances present in the environment. In evaluating chemical exergy, besides temperature and pressure, the difference in a system and environment's chemical composition is also taken into account [11]. Since the temperature of the gases changes significantly by passing through the torch, the assumption of constant specific heats might lead to considerable errors in entropy change calculation. Therefore, the entropy of each gas is determined for each specific state $(T, p)[12]$ :

$$
E \dot{x}=\dot{m}\left[h(T)-h\left(T_{0}\right)-T_{0}\left(s(T)-s\left(T_{0}\right)\right)+e^{c h}+\frac{v^{2}}{2}\right]
$$

where $\dot{m}, h, s, e^{c h}, v$ are the mass flow rate, specific enthalpy and entropy, chemical exergy and velocity of a component. The outlet axial velocity of each stream is assumed to be the same as the axial velocity or speed of the nozzle jet exit. The ideal gas model can be applied for the gas streams since they are at 
the high temperature and low pressure relative to their critical point [13]. Therefore, Equation (6) is written as:

$$
E \dot{x}=\dot{m}\left[h(T)-h\left(T_{0}\right)-T_{0}\left(s(T)-s\left(T_{0}\right)-\operatorname{Rln} \frac{p}{p_{0}}\right)+\mathrm{e}^{c h}+\frac{v^{2}}{2}\right]
$$

For the process combined with combustion reaction, the flow exergy of each reaction component is calculated as below [14]:

$$
E \dot{x}=\dot{m}\left(n_{i}\left[\bar{h}_{f}^{0}+\bar{h}(T)-\bar{h}\left(T_{0}\right)-T_{0}\left(\bar{s}(T)-\bar{s}\left(T_{0}\right)-\bar{R} \ln \left(\frac{y_{i} p}{y_{i} p_{o}}\right)\right)+\mathrm{e}^{c h}\right]+\frac{v^{2}}{2}\right)
$$

where $n_{i}, y_{i}, \bar{h}_{f}^{0}$ and $\bar{h}$ denote, respectively, the number of mole and mole fraction of compound (i), standard enthalpy of formation and enthalpy per mole. When a difference in exergy or flow exergy between states of the same composition is evaluated, the chemical contribution of exergy is canceled, leaving just the difference in the thermomechanical contributions. For such a calculation, it is unnecessary to evaluate the chemical exergy explicitly. Hence, the net exergy destruction can be evaluated from the overall exergy balance of the torch as a control volume in a steady-state condition, as it is expressed in Equation (9). Furthermore, for the combustion reaction at high temperature, chemical exergy contribution to the flow exergy is relatively small and can also be neglected [13]. In the flame spray, both feedstock and carrier gas are passing through the torch, and thus the exergy change of the feedstock is also taken into account:

$$
0=E \dot{x}_{F}-E \dot{x}_{l}^{Q}+E \dot{x}_{i n}^{g a s}-E \dot{x}_{o u t}^{g a s}+E \dot{x}_{\text {in }}^{f}-E \dot{x}_{o u t}^{f}-E \dot{x}_{d}
$$

In the thermal spray process, the heat is generated from the input energy source (electricity or fuel combustion) at $T_{F}$ with an exergy ate of $\left(1-\frac{T_{0}}{T_{F}}\right) \dot{Q}_{F}$. According to Figure $2, T_{F}$ for plasma and flame spray is the plasma jet temperature and adiabatic flame temperature, respectively. The rate of exergy transfer accompanying heat loss at $T_{l}$ is $\left(1-\frac{T_{0}}{T_{l}}\right) \dot{Q}_{l} . T_{l}$ is assumed as the outlet cooling water temperature on the outer surface of the torch, which continuously removes the heat loss. The useful heat is transferred out by the gases and feedstock mixture from the nozzle jet. Accordingly, the exergy efficiency of the torch is evaluated from the thermomechanical exergy of the input-output streams:

$$
\psi_{\text {torch }}=\frac{E \dot{x}_{\text {out }}}{E \dot{x}_{F}}=1-\frac{E \dot{x}_{d}+E \dot{x}_{l}^{Q}}{E \dot{x}_{F}}
$$

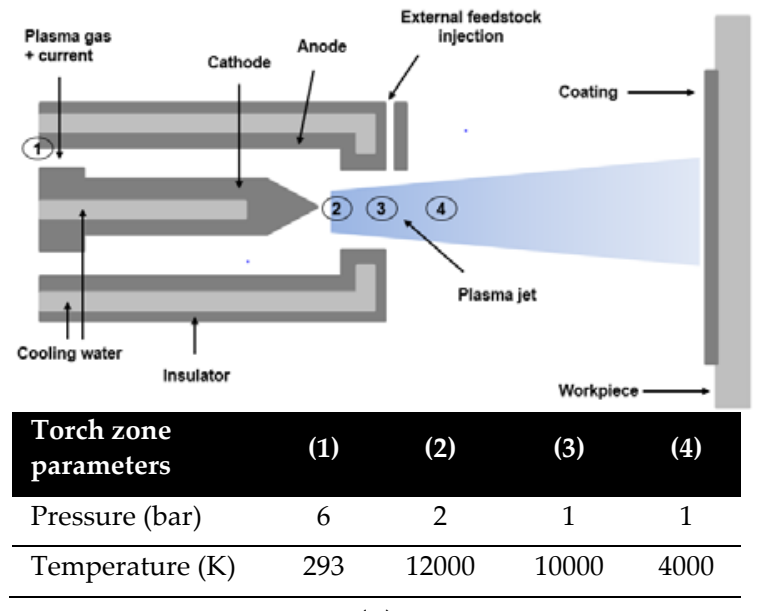

(a)

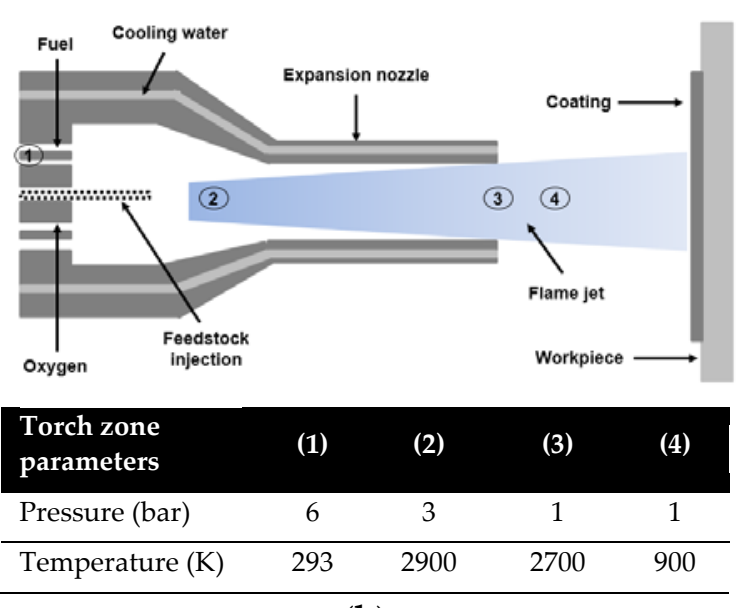

(b)

Figure 2. Schematic of (a) plasma and; (b) flame thermal spray [15]. 
Knowing the total exergy destruction of the torch, energy conversion inefficiencies can be compared by exergy destruction and exergy destruction ratio, as it is expressed in Equation (11):

$$
y_{x}=\frac{E \dot{x}_{d}}{E \dot{x}_{F}}
$$

Effectiveness or task efficiency is defined as a measurement of exergy efficiency. It is simply describing how well a process utilizes energy to convert the raw materials into products. It provides a general realistic measure of the degree to which the performance of a process can be improved $[1,16]$. Effectiveness efficiency [1] is defined as the ratio of the theoretical minimum required exergy to perform a task (such as manufacturing coating) to the actual energy or exergy used as Equation (12):

$$
\varepsilon=\frac{\dot{W}_{\text {min }}}{\dot{W}_{\text {actual }}}
$$

For the thermal spray process, the theoretical minimum required exergy is equivalent to the minimum needed exergy for melting, vaporizing and accelerating feedstock onto the workpiece. Depending on the type of process, it is calculated as below:

$$
\dot{W}_{\min }=\dot{m}_{P}\left[\left(1-\frac{T_{0}}{T_{m}}\right) \Delta h_{m}+\frac{v_{P}^{2}}{2}\right]+\dot{m}_{s} \Delta h_{s, V}
$$

where $\dot{m}_{P} \dot{m}_{s} v_{P}$ are the mass flow rate of the powder and solvent (such as isopropanol) and the powder velocity. Referring to Equation (14), degree of perfection was introduced for resource accounting and evaluation of resources used intensity [11]. For manufacturing processes, it can be defined as the ratio of chemical exergy of the useful output product (for example, the chemical exergy of the manufactured coating) to the sum of the exergy inputs including the exergy of any work and/or heat inputs as well as chemical exergy of all input materials [4,11]. In manufacturing, auxiliary materials are used, which will then not appear in the end products. However, due to their preparation and purification, some might have very high chemical exergy, which is destroyed during a process [4]:

$$
\eta_{p}=\frac{E x_{o u t}}{\sum E x_{i n}}
$$

This accounting applies equally to all participating energy and materials with the same unit (kJ). Therefore, inefficiency of a process in resource consumption can be addressed specifically to energy or material used [4]. To allocate the resources consumption specifically to energy and materials, the degree of energy ratio is defined, which provides useful information for focusing on energy or material reduction for further sustainable resources use effectiveness. According to Equation (15), the degree of energy ratio is defined as the ratio of exergy of input energy to the total input exergy:

$$
X_{F}=\frac{E x_{F}}{\sum E x_{i n}}
$$

\section{Results and Discussion}

\subsection{Experimental Data}

For the analyzed thermal spay processes, the heat is produced, respectively, from the electrical plasma and the fuel combustion in plasma and flame thermal spray. The heat is transferred to the gas mixture under high pressure and temperature that accelerates the resulting flame/gas stream down a nozzle jet [2]. In this study, the functional unit for the comparison was the spray duration (approximately 9 seconds). The powder and solvent were aluminum oxide $\left(\mathrm{Al}_{2} \mathrm{O}_{3}\right)$ and isopropanol $\left(\mathrm{C}_{3} \mathrm{H}_{8} \mathrm{O}\right)$. Feedstock flow rate for powder thermal spray (100 $\mathrm{wt} \%$ powder) and for suspension thermal 
spray (20 $\mathrm{wt} \%$ powder) was approx. $46.5 \mathrm{~g} / \mathrm{min}$ and $57.2 \mathrm{~g} / \mathrm{min}$, respectively. The melting enthalpy of aluminum oxide and enthalpy of vaporization of isopropanol $\left(\mathrm{C}_{3} \mathrm{H}_{8} \mathrm{O}\right)$ were $1.54 \mathrm{~kJ} / \mathrm{g}$ and $0.73 \mathrm{~kJ} / \mathrm{g}$. In HVOF and HVSFS, feedstock (powder/suspension) and the carrier gas (nitrogen) were axially entered into the torch. On the other hand, the feedstock was injected radial at the torch outlet in APS and SPS. The process parameters are summarized in Table 1 . The gas flow rate $(\mathrm{g} / \mathrm{s})$ was calculated from the given flow rate $(\mathrm{L} / \mathrm{min})$ and the gas density.

Table 1. Plasma and flame thermal spray parameters for $\mathrm{Al}_{2} \mathrm{O}_{3}$ coating.

\begin{tabular}{|c|c|c|c|c|c|}
\hline Parameters & APS & SPS & HVOF & HVSFS & Unit \\
\hline $\mathrm{Ar}$ & 39 & 39 & - & - & $\mathrm{L} / \mathrm{min}$ \\
\hline $\mathrm{N}_{2}$ & 7 & 7 & 25 & - & $\mathrm{L} / \mathrm{min}$ \\
\hline $\mathrm{H}_{2}$ & 9 & 9 & - & - & $\mathrm{L} / \mathrm{min}$ \\
\hline $\mathrm{O}_{2}$ & - & - & 320 & 320 & $\mathrm{~L} / \min$ \\
\hline $\mathrm{C}_{2} \mathrm{H}_{4}$ & - & - & 90 & 90 & $\mathrm{~L} / \mathrm{min}$ \\
\hline Current & 550 & 550 & - & - & A \\
\hline Power & 39 & 39 & - & - & $\mathrm{kW}$ \\
\hline Cooling power & 19.2 & 19.2 & 12.6 & 12.6 & $\mathrm{~kW}$ \\
\hline Water flow rate & 13.5 & 13.5 & 28.8 & 28.8 & $\mathrm{~L} / \mathrm{min}$ \\
\hline Inlet water temperature & 18.5 & 18.5 & 23.7 & 23.7 & ${ }^{\circ} \mathrm{C}$ \\
\hline Outlet water temperature & 39 & 39 & 30 & 30 & ${ }^{\circ} \mathrm{C}$ \\
\hline Feedstock & $\begin{array}{c}\mathrm{Al}_{2} \mathrm{O}_{3} \\
\text { Powder }\end{array}$ & $\begin{array}{l}20 \mathrm{wt} \% \mathrm{Al}_{2} \mathrm{O}_{3} \\
\text { in isopropanol }\end{array}$ & $\begin{array}{c}\mathrm{Al}_{2} \mathrm{O}_{3} \\
\text { Powder }\end{array}$ & $\begin{array}{l}20 \mathrm{wt} \% \mathrm{Al}_{2} \mathrm{O}_{3} \\
\text { in isopropanol }\end{array}$ & - \\
\hline $\mathrm{Al}_{2} \mathrm{O}_{3}$ & 46.6 & 11.6 & 46.6 & 11.6 & $\mathrm{~g} / \mathrm{min}$ \\
\hline $\mathrm{C}_{3} \mathrm{H}_{8} \mathrm{O}$ & - & 45.6 & - & 45.6 & $\mathrm{~g} / \mathrm{min}$ \\
\hline Nozzle jet axial velocity $[2,15]$ & 600 & 600 & 1200 & 1200 & $\mathrm{~m} / \mathrm{s}$ \\
\hline
\end{tabular}

\subsection{Effectiveness Analysis}

For exergetic analysis of the process, it was assumed that the exergy of the input energy (electricity, fuel) was equivalent to its energy value. Figure 2 shows the physical conditions of the torch. The entrance torch pressure was measured from the gas container pressure and the exit pressure was the atmospheric pressure. Inlet temperature was assumed as atmospheric temperature. Pressures and temperatures inside the torch and the torch outlet are well defined in the literature $[2,15]$.

As demonstrated in Figure 3, with an assumption of steady-state condition, specific enthalpy and entropy change of the gas mixture are schematically illustrated in an enthalpy-entropy (h-s) diagram. Generally, due to the high temperature in plasma, the specific enthalpy is higher compared to flame spray [2]. However, considering the same spray duration as the function unit in this work, the input enthalpy of the flame spray was higher than plasma spray. It is observed that the enthalpy of gas mixture is increased (0-1). In flame spray, there is a reduction of enthalpy and an increase of entropy as the temperature and pressure are reduced from combustion chamber to the nozzle jet $\left(1^{\prime}-1\right)$. The heat loss is removed at the constant pressure of the torch (1-2). Enthalpy decreases as the gas mixture leaves the torch (2-3). The total output gas enthalpy is the sum of thermal and kinetic energy of gases in plasma/flame jet. However, the kinetic energy is relatively small compared to the thermal energy of the jet, especially for the case of plasma spray $[2,15]$.

Also the results from entropy change are used for calculation of the physical exergy destruction. It is shown that the entropy generation of the flame thermal spray is higher than of the plasma spray because of the additional irreversibility associated with energy conversion of the combustion, which converts a fuel and oxygen stream into the products of combustion.

Knowing the theoretical minimum exergy from Equation (13) and the actual consumed exergy in Table 1, effectiveness efficiency was calculated by Equation (12). Theoretical minimum required exergy was evaluated by the given parameters in Table 1, melting enthalpy of alumina and vaporization enthalpy of the isopropanol. The results are compared for thermal spray processes in Figure 4. 


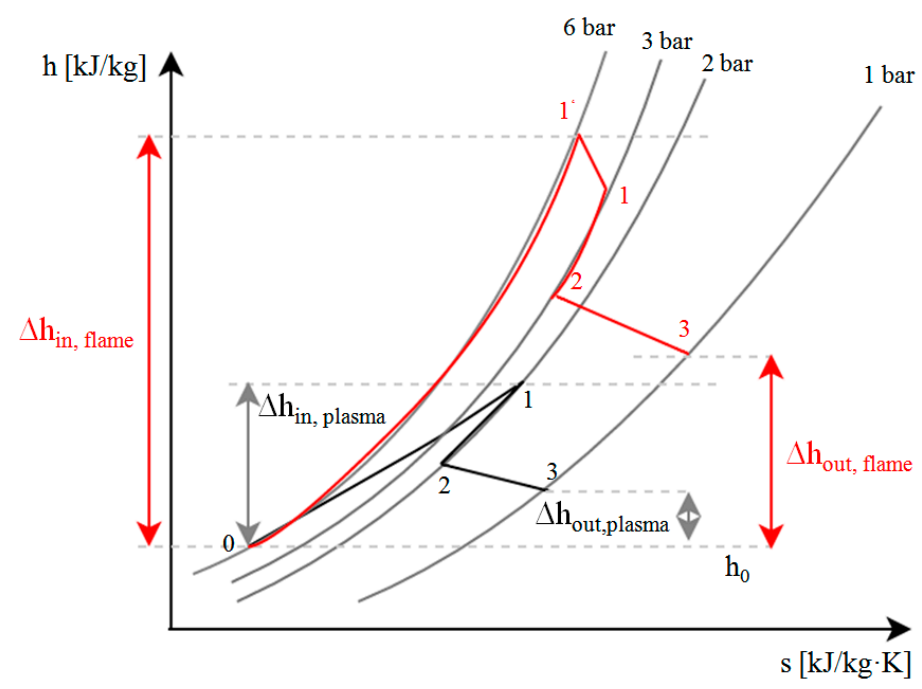

Figure 3. Specific enthalpy and entropy comparison of plasma and flame thermal spray in enthalpy-entropy $(\mathrm{h}-\mathrm{s})$ diagram for the same spray duration.

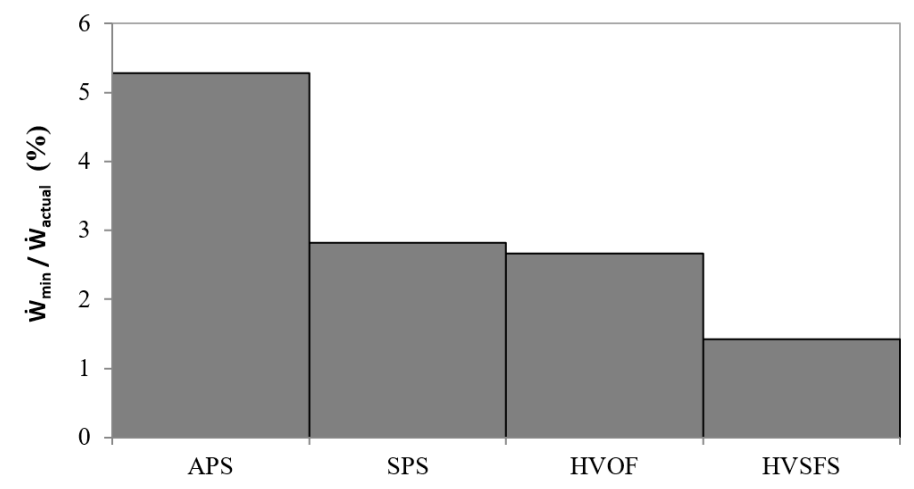

Figure 4. Comparison of effectiveness efficiency for thermal spray processes.

Effectiveness efficiency measures the process performance in doing a task encompassing the efficiency of the energy and material use. It was observed that flame thermal spray in general had the lower effectiveness efficiency compared to plasma spray. Furthermore, because of the lower vaporization energy of $\mathrm{C}_{3} \mathrm{H}_{8} \mathrm{O}$ than melting energy of $\mathrm{Al}_{2} \mathrm{O}_{3}$, required minimum theoretical exergy for the suspension feedstock was lower compared to $100 \mathrm{wt} \%$ powder feedstock.

The given parameters in Table 1, Figures 2 and 3 were applied for the torch energy and exergy balances. From the energy analysis, Equations (1) to (4), it can be seen that the thermal efficiency of the flame spray was much higher than the plasma spray, which is interpreted by the lower torch temperature and respective conductive and radiative heat losses. However, comparison of thermal spray processes based on only thermal efficiency did not give concrete information about the effectiveness of the energy conversion. Therefore, exergy-based methods, Equations (5) to (11), were also carried out for evaluation of the energy conversion efficiency in accordance with entropy generation. The results were calculated based on thermomechanical/physical exergy of the torch. From the exergy analysis, exergy destruction rate contributed as the major inefficiencies followed by exergy rate of heat loss, while the heat losses were considered as the total inefficiencies from the energy analysis. The results are summarized in Table 2. 
Table 2. Energy and exergy balances for the thermal spray torch.

\begin{tabular}{|c|c|c|c|c|c|c|c|c|c|}
\hline $\begin{array}{c}\text { Spray } \\
\text { Process }\end{array}$ & $\begin{array}{c}\dot{E n_{F}} \\
(\mathbf{k W})\end{array}$ & $\begin{array}{c}\dot{E n_{l}^{Q}} \\
(\mathbf{k W})\end{array}$ & $\begin{array}{l}E n_{o u t} \\
(\mathrm{~kW})\end{array}$ & $\begin{array}{c}\dot{E x_{F}} \\
(\mathbf{k W})\end{array}$ & $\begin{array}{c}\dot{E x_{l}^{Q}} \\
(\mathbf{k W})\end{array}$ & $\begin{array}{c}\dot{E} x_{d} \\
(\mathbf{k W})\end{array}$ & $\begin{array}{l}E x_{o u t} \\
(\mathbf{k W})\end{array}$ & $\eta(\%)$ & $\Psi(\%)$ \\
\hline APS & 39 & 19.2 & 19.8 & 37.8 & 1.17 & 23.5 & 13.1 & 50.8 & 34.6 \\
\hline SPS & 39 & 19.2 & 19.8 & 37.8 & 1.17 & 23.5 & 13.1 & 50.8 & 34.6 \\
\hline HVOF & 84 & 12.6 & 71.4 & 74.9 & 0.81 & 35.5 & 38.6 & 85 & 51.5 \\
\hline HVSFS & 84 & 12.6 & 71.4 & 74.9 & 0.81 & 37.7 & 36.4 & 85 & 48.6 \\
\hline
\end{tabular}

As it was expected, exergy destruction associated with flame spray was higher than that of plasma spray due to the irreversibilities of the combustion and change in gas compositions. However, as the exergy input for the flame spray was higher than plasma spray for the same spray duration, its exergy destruction ratio was lower compared to plasma spray, see Figure 5.

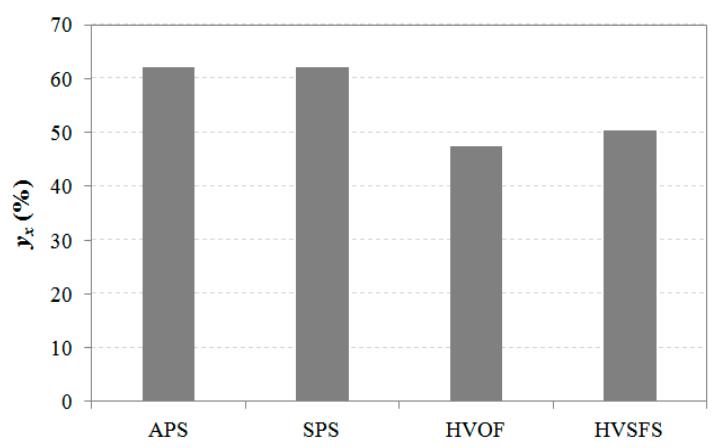

Figure 5. Comparison of exergy destruction ratio for thermal spray processes.

It can be concluded that suspension flame spray in general had the highest destruction of the input exergy or the worst effectiveness of the energy conversion.

\subsection{Resource Accounting}

According to the definition of the degree of perfection, the chemical exergy of the energy and material streams need to be taken into account. Chemical exergy of the participating components are given in literature [11] and listed in Table 3. As represented in Table 4, exergy of each stream was obtained from the chemical exergy and the quantity of each stream. The quantities of streams were calculated from the process parameters given in Table 1 and spray duration. Note that the exergy of the $\mathrm{Al}_{2} \mathrm{O}_{3}$ coating was considered as the useful output exergy. The very low value of degree of perfection showed the high amount of input resources (energy, materials) was consumed inefficiently and lost. Due to vaporization and loss of $\mathrm{C}_{3} \mathrm{H}_{8} \mathrm{O}$ as an auxiliary material, the degree of perfection for suspension thermal spray was lower than that of powder thermal spray.

Table 3. Chemical exergy of the applied materials in thermal spray.

\begin{tabular}{ccc}
\hline Materials & Molar mass $(\mathrm{g} / \mathbf{m o l})$ & Chemical exergy $($ ex $)(\mathbf{k J} / \mathbf{m o l})$ \\
\hline $\mathrm{Al}_{2} \mathrm{O}_{3}$ & 101.9 & 200 \\
$\mathrm{Ar}$ & 39.9 & 11.7 \\
$\mathrm{~N}_{2}$ & 28 & 0.72 \\
$\mathrm{H}_{2}$ & 2 & 236.1 \\
$\mathrm{O}_{2}$ & 32 & 4 \\
$\mathrm{C}_{2} \mathrm{H}_{4}$ & 28 & 1361 \\
$\mathrm{C}_{3} \mathrm{H}_{8} \mathrm{O}$ & 60 & 1998.6 \\
\hline
\end{tabular}


Table 4. Input-output exergy and degree of perfection of thermal spray $\mathrm{Al}_{2} \mathrm{O}_{3}$ coating; functional unit: spray duration.

\begin{tabular}{|c|c|c|c|c|c|c|c|c|}
\hline \multirow{2}{*}{ Streams } & \multicolumn{2}{|c|}{ APS } & \multicolumn{2}{|c|}{ SPS } & \multicolumn{2}{|c|}{ HVOF } & \multicolumn{2}{|c|}{ HVSFS } \\
\hline & $m(\mathrm{~g})$ & $\begin{array}{l}\text { Exergy } \\
\text { (kJ) }\end{array}$ & $m(\mathrm{~g})$ & $\begin{array}{l}\text { Exergy } \\
(\mathrm{kJ})\end{array}$ & $m(\mathrm{~g})$ & $\begin{array}{l}\text { Exergy } \\
(\mathrm{kJ})\end{array}$ & $m(\mathrm{~g})$ & $\begin{array}{l}\text { Exergy } \\
(\mathrm{kJ})\end{array}$ \\
\hline \multicolumn{9}{|l|}{ Input materials } \\
\hline $\mathrm{Al}_{2} \mathrm{O}_{3}$ & 6.33 & 12.4 & 1.58 & 3.1 & 6.33 & 12.4 & 1.58 & 3.1 \\
\hline Ar & 9.66 & 2.8 & 9.66 & 2.8 & - & - & - & - \\
\hline $\mathrm{N}_{2}$ & 1.21 & 0.03 & 1.21 & 0.03 & 4.3 & 0.1 & 4.3 & 0.1 \\
\hline $\mathrm{H}_{2}$ & 0.11 & 13.3 & 0.11 & 13.3 & - & - & - & - \\
\hline $\mathrm{O}_{2}$ & - & - & - & - & 63.5 & 7.9 & 63.5 & 7.9 \\
\hline $\mathrm{C}_{2} \mathrm{H}_{4}$ & - & - & - & - & 14.7 & 742 & 14.7 & 742 \\
\hline $\mathrm{C}_{3} \mathrm{H}_{8} \mathrm{O}$ & - & - & 6.33 & 211 & - & - & 6.33 & 211 \\
\hline \multicolumn{9}{|l|}{ Input energy } \\
\hline Electricity & - & 325 & - & 325 & - & - & - & - \\
\hline Sum of inputs & - & 353.5 & - & 555 & - & 762.4 & - & 965 \\
\hline \multicolumn{9}{|l|}{ Output } \\
\hline $\mathrm{Al}_{2} \mathrm{O}_{3}$ coating & 0.36 & 0.7 & 0.12 & 0.24 & 1.36 & 2.67 & 0.46 & 0.9 \\
\hline $\begin{array}{c}\text { Degree of } \\
\text { perfection }\left(\eta_{p}\right)\end{array}$ & \multicolumn{2}{|c|}{$2 \times 10^{-3}$} & \multicolumn{2}{|c|}{$4.3 \times 10^{-4}$} & \multicolumn{2}{|c|}{$3.5 \times 10^{-3}$} & \multicolumn{2}{|c|}{$9.3 \times 10^{-4}$} \\
\hline
\end{tabular}

Furthermore, as it is shown in Figure 6, the lower degree of energy ratio of suspension compared to powder thermal spray underlines that suspension thermal spray was more associated with material loss than energy loss.

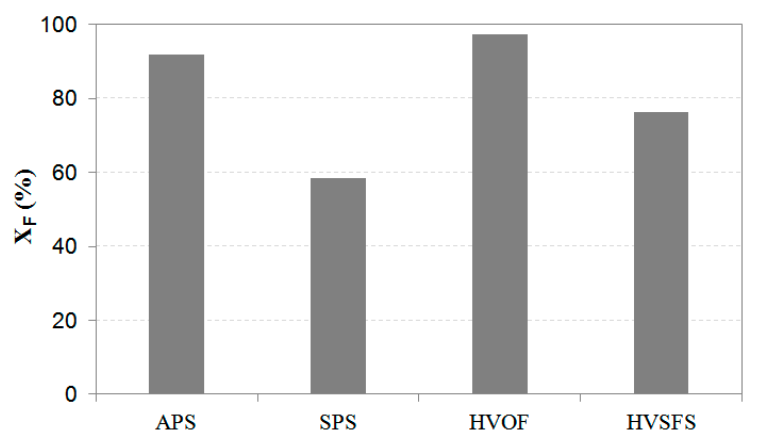

Figure 6. Comparison of degree of energy ratio for thermal spray processes.

\section{Conclusions}

Thermodynamic energy and exergy analysis were conducted to compare the efficiency and effectiveness of the energy conversion along with resources used evaluation in thermal spray processes. For the torch energy conversion efficiency analysis, it was pointed out that thermal efficiency was not a suitable indicator for the comparison of thermal spray processes as the cooling capacity for plasma and flame spray varied in accordance with each process characteristic.

Considering the same spray duration, flame spray showed the lower effectiveness efficiency compared to plasma spraying, which emphasized the higher inefficiency of the energy used. The big difference between the results of effectiveness efficiency and exergy efficiency was because of different analysis boundaries. For effectiveness efficiency evaluation, the analysis boundary was extended to the coated workpiece and, therefore, major energy and material losses occurred from the nozzle exit to the workpiece. The results of exergy destruction analysis highlighted the energy conversion inefficiency in the torch. It was indicated that the exergy destruction associated with flame spray was higher than that of plasma spray due to the combustion and change in gas compositions. Additionally, using suspension feedstock increased the exergy destruction.

From resource accounting, and according to the presented results in Table 4, the lower value of degree of perfection for suspension compared to powder thermal spray signified the participation and 
loss of high exergetic auxiliary material $\left(\mathrm{C}_{3} \mathrm{H}_{8} \mathrm{O}\right)$ without appearing in the final manufactured coating. This result can also be seen in Figure 6 as the degree of energy ratio was lower for suspension thermal spray processes. For powder thermal spray processes, on the other hand, the biggest part of exergy losses was associated with inefficient energy utilization.

For resource saving and sustainable improvement of thermal manufacturing processes, the same approach can be used for comparison of different forms of feedstock, process techniques and auxiliary materials.

Acknowledgments: Financial support was provided by the Graduate School of Excellence Advanced Manufacturing Engineering (GSaME) from the University of Stuttgart and is greatly appreciated.

Author Contributions: Kamran Taheri as the first and corresponding author was responsible for the idea, analysis and writing of the paper. Mohamed Elhoriny and Martin Plachetta contributed in experimental and revision parts of the work; Rainer Gadow was the supervisor and the institute's director. All authors have read and approved the final manuscript.

Conflicts of Interest: The authors declare no conflict of interest.

\section{Nomenclature}

\begin{tabular}{ll}
$\mathrm{Ar}$ & argon \\
$\mathrm{C}_{2} \mathrm{H}_{4}$ & ethylene \\
$\mathrm{C}_{3} \mathrm{H}_{8} \mathrm{O}$ & isopropanol \\
$\dot{E n}$ & energy rate $(\mathrm{kW})$ \\
$\dot{E x}$ & exergy rate $(\mathrm{kW})$ \\
$E x$ & exergy $(\mathrm{kJ})$ \\
$e x$ & chemical exergy $(\mathrm{kJ} / \mathrm{mol})$ \\
$h$ & specific enthalpy $(\mathrm{kJ} / \mathrm{g})$ \\
$\bar{h}$ & molar enthalpy $(\mathrm{kJ} / \mathrm{mol})$ \\
$\bar{h}_{f}^{0}$ & standard enthalpy of formation $(\mathrm{kJ} / \mathrm{mol})$ \\
$\mathrm{H}_{2}$ & hydrogen \\
$\dot{m}$ & mass flow rate $(\mathrm{g} / \mathrm{s})$ \\
$M$ & molar mass $(\mathrm{g} / \mathrm{mol})$ \\
$\mathrm{O}_{2}$ & oxygen \\
$n$ & number of moles \\
$\mathrm{N}_{2}$ & nitrogen \\
$p$ & pressure $(\mathrm{bar})$ \\
$\bar{R}$ & gas constant $(\mathrm{J} / \mathrm{mol} \cdot \mathrm{K})$ \\
$s$ & specific entropy $(\mathrm{kJ} / \mathrm{kg} \cdot \mathrm{K})$ \\
$S$ & entropy $(\mathrm{kJ} / \mathrm{K})$ \\
$T$ & temperature $\left({ }^{\circ} \mathrm{C}\right.$ or K) \\
$v$ & velocity $(\mathrm{m} / \mathrm{s})$ \\
$\dot{W}$ & work rate $(\mathrm{kW})$ \\
$y_{i}$ & mole fraction \\
$y_{x}$ & exergy destruction ratio $(\%)$ \\
$\mathrm{Subscript}$ & \\
0 & ambient $/$ atmospheric condition \\
$F$ & input energy \\
$d$ & destruction \\
$e n$ & energy \\
$g e n$ & generation \\
in & input stream \\
& \\
\hline &
\end{tabular}




$\begin{array}{ll}j & \text { jet } \\ l & \text { loss } \\ m & \text { melt } \\ \text { min } & \text { minimum } \\ \text { mix } & \text { mixture } \\ \text { out } & \text { outlet stream } \\ P & \text { powder } \\ s & \text { solvent } \\ \text { v } & \text { vaporization } \\ w & \text { water } \\ \text { Superscript } & \\ c h & \text { chemical exergy } \\ f & \text { feedstock } \\ Q & \text { heat } \\ \text { Greek letter } & \\ \eta & \text { energy efficiency (\%) } \\ \eta_{P} & \text { degree of perfection (\%) } \\ \Psi & \text { exergy efficiency (\%) } \\ \varepsilon & \text { effectiveness efficiency (\%) } \\ X_{F} & \text { degree of energy ratio (\%) } \\ \text { Abbreviations } & \\ \text { APS } & \text { Atmospheric Plasma Spray } \\ \text { HVOF } & \text { High Velocity Oxy-Fuel Flame Spray } \\ \text { HVSFS } & \text { High Velocity Suspension Flame Spray } \\ \text { SPS } & \text { Suspension Plasma Spray } \\ & \end{array}$

\section{References}

1. Bakshi, B.R.; Gutowski, T.G.; Sekulic, D.P. Thermodynamics and Destruction of Resources, 1st ed.; Cambridge University Press: Cambridge, UK, 2011; pp. 38-43, 167-189.

2. Davis, J.R. Handbook of Thermal Spray Technology, 1st ed.; ASM International: Materials Park, OH, USA, 2004; pp. 3-5, 53-59.

3. Jovane, F.; Westkämper, E.; Williams, D. The ManuFuture Road, 1st ed.; Springer: Berlin/Heidelberg, Germany, 2009; pp. 33-40.

4. Gutowski, T.G.; Branham, M.S.; Dahmus, J.B.; Jones, A.J.; Thiriez, A.; Sekulic, D.P. Thermodynamic Analysis of Resources Used in Manufacturing Processes. Environ. Sci. Technol. 2009, 43, 1584-1590. [CrossRef] [PubMed]

5. Gadow, R.; Killinger, A.; Kuhn, M.; Martinez, L.D. Verfahren und Vorrichtung zum Thermischen Spritzen von Suspensionen. German Patent DE102005038453A1, 8 February 2007. (In German).

6. Killinger, A.; Kuhn, M.; Gadow, R. High-Velocity Suspension Flame Spraying (HVSFS), A New Approach for Spraying Nanoparticles with Hypersonic Speed. Surf. Coat. Technol. 2006, 201, 1922-1929. [CrossRef]

7. Li, C.J.; Yang, G.J.; Wang, Z. Effect of Spray Parameters on the Structure of Nano-Structured $\mathrm{TiO}_{2}$ Deposits by Liquid Flame Spray Process. In Proceedings of the International Thermal Spray Conference, Essen, Germany, 4-6 March 2002; pp. 544-549.

8. Taheri, K.; Gadow, R.; Killinger, A. Exergy analysis as a developed concept of energy efficiency optimized processes: The case of thermal spray processes. In Proceedings of the 47th CIRP Conference on Manufacturing Systems, Windsor, ON, Canada, 28-30 April 2014; Volume 17, pp. 511-516.

9. Rant, Z. Exergy, a new word for "technical available work". Forschung auf dem Gebiete des Ingenieurwesens 1956, 22, 36-37. (In German) 
10. Wall, G. Exergy-A Useful Concept within Resource Accounting. Available online: http://www.exergy.se/ ftp/ex77c.pdf (accessed on 20 June 2016).

11. Szargut, J.; Morris, D.R.; Steward, F.R. Exergy Analysis of Thermal, Chemical, and Metallurgical Processes; Hemisphere Publishing: New York, NY, USA, 1988.

12. Bejan, A.; Tsatsaronis, G.; Moran, M. Thermal Design \& Optimization; Wiley: New York, NY, USA, 1996.

13. Cengel, Y.; Boles, M.A. Thermodynamics: An Engineering Approach, 4th ed.; McGraw-Hill: New York, NY, USA, 2006; pp. 326-328.

14. Moran, M.J.; Shapiro, H.N. Fundamentals of Engineering Thermodynamics, 6th ed.; Wiley: Hoboken, NY, USA, 2007; pp. 755-759.

15. Schnieder, K.E.; Belashenko, V.; Dratwinski, M.; Siegmann, S.; Zagorski, A. Thermal Spraying for Power Generation Components; Wiley: Weinheim, Germany, 2006; pp. 45-54, 145-151.

16. Frazier, R.S. An Exergy Diagnostic Methodology for Energy Management in Manufacturing. Ph.D. Thesis, Oklahoma State University, Norman, OK, USA, 2006.

(C) 2016 by the authors; licensee MDPI, Basel, Switzerland. This article is an open access article distributed under the terms and conditions of the Creative Commons Attribution (CC-BY) license (http://creativecommons.org/licenses/by/4.0/). 